Leading article/Uvodnik

\title{
Effects of nursing care on patient outcomes: times to reflect and to take decisions
}

\author{
Učinki zdravstvene nege na izid zdravljenja: čas za refleksijo in ukrepanje
}

\author{
Alvisa Palese
}

There is important recent scientific evidence published in The Lancet by Aiken and colleagues (2014) who have documented the effects of nursing care including about 300 hospitals in 9 European Union countries and 2 countries of the European Free Trade Association (Switzerland and Norway). From the findings which documented outcomes from 422,730 patients, even in the European context with its nursing roles and work conditions that are different from those documented in the United States of America, Aiken and colleagues (2014) found that for each additional surgical patient managed by a registered nurse, there is an increase of $7 \%$ in the risk of mortality at 30 days. From the same study, patients cared for at hospitals in which $60 \%$ of nurses had a bachelor's degree, who attended an average of six patients, had a mortality rate almost $30 \%$ lower than patients at hospitals in which only $30 \%$ of nurses had a bachelor's degree.

This is the first time that such evidence has been produced in the European context, confirming what has already been reported in different health-care settings around the world. Nurses, at the educational, clinical, and organizational level, have always known and professed that the number of nurses and their educational level make a difference on patient outcomes. However, only recently has gradually accumulating evidence based on research confirmed the relation between quantity and quality of nursing care and patient clinical outcomes. Therefore, decisionmakers responsible for re-designing and re-thinking the health care systems in a context of limited resources should consider this evidence when making decisions for the future care of the citizens.

The study performed by Aiken and colleagues (2014) has already become a landmark in the history of European nursing and suggests undertaking several decisions in the field of nursing education and workforce organization. To begin with, this is the first panEuropean study that has been under way since 1999, when throughout the Bologna Process, education began to be harmonised in different cycles (Bachelor, Master, Doctorate) influencing at different levels also nursing education (Palese, et al., 2014). Secondly, this is the first study documenting the variability within and between countries with respect to the nurse-to-patient ratio (=the number of patients managed, on average, by each nurse) (Palese \& Watson, 2014). According to the findings, there is a range from a minimum of 3.4 patients (Norway) to a maximum of 17.9 patients (Spain) for each nurse. The effect of having few nurses at the bedside is immediate: workloads increase, necessary care is not assured and the occurrence of missed care also increases; adverse events such as falls, pressure sores, reduced autonomy in activities of daily living, infections associated with health-care practices and not lastly, an increased risk of mortality, are more probable; emotional exhaustion and frustration may increase among nurses because they cannot offer the patients the best level of care that they are able to and would offer according to their professional and ethical values, knowledge and competence.

Several countries are trying to deal with the current debilitating economic crisis. Cost-containment measures have been adopted and most of these are affecting nursing education and the workforce. Among other measures documented, some health-care settings cannot hire new graduates of which they have dramatic need to ensure the safety of their patients. Recent graduates remain unemployed for a long time, losing the skills in which the country has invested through degree programmes as well as the clinical training offered by hospitals and communities which have contributed to preparing future generations of nurses.

Patients who lack proper nursing care are exposed to more risks and complications, requiring longer hospital stays and additional costs that could be avoided if they were properly assisted by an adequate number of wellprepared nurses. In addition, aiming to maintain their

Alvisa Palese, DNurs, MSN, BCN, RN, Associate Professor in Nursing Science, Udine University, School of Nursing, Italy

Correspondence e-mail/Kontaktni e-naslov: alvisa.palese@uniud.it 
competence and skills, many of the newly graduated decide to leave their countries, reaching those where nurses are appreciated and employed to protect patient safety. This emerging migration worsens the situation of several countries who are losing new generations of nurses, leaving those senior nurses unsupported by new energy and competence which is absolutely needed in the complex health-care environment. In fact, only when different generations can work together in an integrated manner with each other, exchanging knowledge and expertise, can the profession grow (Canzan, et al., 2013).

Through the abovementioned study we have concrete evidence of the effects of European nursing care on patients, which is no longer merely the opinion of clinical nurses, nursing educators and managers. Reporting similar evidence documented previously for non-European countries, we were always alerted by decision-makers regarding contexts that were too different from our own, and therefore the results could not be generalised. Today, the countries involved in the research include Spain, Belgium, England, Finland, Ireland, the Netherlands, and Sweden as well as Norway and Switzerland, some of which share the same economic difficulties. There is a need for an immediate reaction with policies capable of integrating this 'new' evidence into daily practice and/or recommendations for nursing education and workforce issues. Communicating this evidence to our stakeholders at their different levels is urgently required: each of us may contribute to influencing the decisions regarding the future of nursing.

\section{Literature}

Aiken, L.H., Sloane, D.M., Bruyneel, L., Van den Heede, K., Griffiths, P., Busse, R., et al., 2014. Nurse staffing and education and hospital mortality in nine European countries: a retrospective observational study. Lancet, 383(9931), pp. 1824-1830.

http://dx.doi.org/10.1016/S0140-6736(13)62631-8

PMid:24581683; PMCid:PMC4035380

Canzan, F., Saiani, L., Mortari, L. \& Ambrosi, E., 2013. When patients talk about care: a qualitative phenomenological study. Assistenza Infermieristica e Ricerca, 32(4), pp. 205-212.

http://dx.doi.org/10.1702/1381.15358

PMid:24441465

Palese, A., Zabalegui, A., Sigurdardottir, A.K., Bergin, M., Dobrowolska, B., Gasser, C., et al., 2014. Bologna process, more or less: nursing education in the European economic area: a discussion paper. International Journal of Nursing Education Scholarship, 11(1).

http://dx.doi.org/10.1515/ijnes-2013-0022

PMid:24695045

Palese, A. \& Watson, R., 2014. Nurse staffing and education in Europe: if not now, when? Lancet, 383(9931), pp. 1789-1790. http://dx.doi.org/10.1016/S0140-6736(14)60188-4

PMid:24581681

Cite as/Citirajte kot:

Palese, A., 2014. Effects of nursing care on patient outcomes: times to reflect and to take decisions. Obzornik zdravstvene nege, 48(3), pp. 164-165. http://dx.doi.org/10.14528/snr.2014.48.3.23 